\section{Expatriação e Processos de Aprendizagem Organizacional: um estudo de casos múltiplos}

\author{
Ana Virgínia Alberici Giordani Bertolini e Fabiano Larentis
}

\section{RESUMO}

Ao considerar a globalização uma aliada à expansão das estratégias das organizações na internacionalização de seus negócios, a expatriação de empregados surge como um recurso de gestão de pessoas e, assim, oportuniza benefícios para as empresas e para o crescimento profissional e pessoal dos indivíduos. Portanto, este artigo teve como objetivo analisar a contribuição da expatriação para os processos de aprendizagem organizacional. Desenvolveu-se, para tanto, um estudo de casos múltiplos, com a participação cinco de empresas exportadoras do Rio Grande do Sul. A coleta de dados deu-se através de entrevistas com empregados que já foram expatriados ou que ainda se encontram em processo de expatriação, observações e pesquisa documental. Como resultados, pode-se observar que a expatriação tende a desencadear processos de aprendizagem organizacional que se encontram embutidos nas atividades cotidianas do indivíduo. Identificou-se que os empregados aprenderam, a partir de suas experiências, a enfrentar um problema ou desafio, através da reflexão, interação e colaboração com colegas. Além disso, a partir da expatriação, o expatriado enxerga a sua própria cultura sob uma nova ótica, toma conhecimento de outras culturas organizacionais e identifica novas formas de lidar com pessoas.

Palavras-chave: aprendizagem organizacional; expatriação; processos de aprendizagem; maneiras de aprendizagem.

\section{Expatriation and Organizational Learning Processes: a multiple case study}

\section{ABSTRACT}

By considering globalization as an alliance with the expansion of organizations' strategies in the internationalization of their businesses, the expatriation of employees emerges as a people management resource and, thus, offers benefits for companies and for the professional and personal growth of individuals. This article aimed to analyze the contribution of expatriation to organizational learning processes. A multi-case study was developed with the participation of four export companies from the state of Rio Grande do Sul, through interviews with employees who were already expatriates or who are still in the process of expatriation, as well as observation and documents. As results, it can be observed that the expatriation tends to trigger organizational learning processes that are embedded in the daily activities of the individual. It has been identified that employees learned from their experiences how to face a problem or challenge through reflection, interaction and collaboration with colleagues. In addition, with expatriation, the expatriate sees his or her own culture in a new perspective, becomes aware of other organizational cultures and identifies new ways of dealing with people.

Keywords: organizational learning; expatriation; learning processes; learning ways.

Recebido em: 08/12/2017 Revisado em: 10/05/2018 Aprovado em: 11/06/2018

Check for updates

Ana Virgínia Alberici Giordani Bertolini (iD,

Faculdade Fisul, Brasil

Mestra em Administração,

Universidade de Caxias do Sul, Brasil

ana_vgiordani@hotmail.com

\section{Fabiano Larentis (iD,}

Universidade de Caxias do Sul, Brasil Doutor em Administração,

Universidade Federal do Rio Grande do Sul, Brasil

flarenti@ucs.br 


\section{Introdução}

A globalização e a liberalização do comércio e serviços ao redor do mundo criaram uma oportunidade para as empresas operarem em diversos mercados e ambientes geográficos (Rose, Ramalu, Uli, \& Kumar, 2010; Park \& Mense-Petermann, 2014). O incremento da competitividade diante da globalização e a onipresença em diversos mercados fazem da inserção internacional uma estratégia necessária para a sobrevivência das organizações, o que inclui as práticas de gestão de pessoas devido ao maior número de indivíduos cruzando fronteiras (Baruch \& Altman, 2002; Klotzle, 2002).

Na prática da gestão internacional, um desafio considerado essencial consiste em conectar o conhecimento distribuído entre as diferentes localizações da empresa e fazer uso produtivo desse conhecimento para a obtenção de vantagem competitiva por parte das organizações (Park \& Mense-Petermann, 2014). Os indivíduos são ativos estratégicos que influenciam a probabilidade de gerar e sustentar vantagem competitiva nas empresas (Tan \& Mahoney, 2006; Cavusgil, Knight, \& Riesenberger, 2010). Quando esses são expatriados, necessitam desempenhar diferentes atribuições na organização, pois são como representantes da empresa matriz, gestores para a subsidiária local, residentes no país sede da subsidiária, cidadãos locais ou com dupla nacionalidade e especialistas (Rahim, 1983).

Dutra (2002), ao trabalhar a gestão de pessoas, cita a expatriação como uma forma de movimentação de pessoas e considera a expatriação uma transferência de empregado que envolve mudança de país por um período superior a seis meses. A partir da transmissão do conhecimento para outros indivíduos na subsidiária ou para indivíduos da matriz, os indivíduos aprendem através da própria experiência de compartilhamento (Oddou, Osland, \& Blakeney, 2009; Chang \& Smale, 2013; Fee, Gray, \& Lu, 2013). A expatriação, portanto, permite possibilidades de aprendizado atreladas a desafios internacionais, interferindo no incremento do conhecimento e na carreira dos envolvidos (Gallon \& Scheffer, 2015)

No processo de expansão internacional, a aprendizagem organizacional pode incrementar a intensidade do conhecimento das companhias como um pré-requisito para enfrentar as tendências da globalização (Prange, 2001). O papel dos indivíduos envolvidos no processo de competitividade e transformações mercadológicas implica em uma melhor qualificação e capacitação, o que acaba por refletir no preparo da própria organização em estabelecer estratégias e processos de expansão internacional (Rose et al., 2010). Ao vivenciar o cotidiano e aprender com ele, os empregados enviados para trabalhar pelas organizações fora de seu país de origem, os expatriados, tornam-se mais propensos a manterem-se engajados no trabalho (Porath, Spreitzer, Gibson, \& Garnett, 2012).

Pelo fato de a aprendizagem organizacional ser necessária para o sucesso das organizações, uma maior compreensão do tema permite melhorar o seu desempenho e a prosperidade dos seus membros (Argote, 
2011). A aprendizagem organizacional pode ser vista como um processo contínuo de criação e apropriação de conhecimentos novos em nível individual, grupal e organizacional, uma vez que se refere a processos de aprendizagem individual e coletivos (Prange, 2001). Convém destacar que neste estudo considera-se a aprendizagem como um fenômeno cultural e social, não somente cognitivo, assim como de caráter processual (Nicolini, Gherardi, \& Yanow, 2003; Gherardi, 2005; Antonello \& Godoy, 2010)

Chiva, Ghauri e Alegre (2014) afirmam que a internacionalização oferece às organizações diferentes experiências que Ihes permitem aprender ou desenvolver novos conhecimentos. Os autores ainda sustentam que empresas que operam em mercados internacionais geram mais conhecimento do que os seus concorrentes que operam apenas no mercado nacional, por meio da aprendizagem de fontes externas. Nesse ínterim, tendo em consideração empresas que optam por expatriar empregados, em função da necessidade de controlar as atividades das subsidiárias, para complementar conhecimentos dos membros da equipe através de pessoas de sua confiança (Tanure, Evans, \& Pucik, 2007; Freitas, 2010), percebe-se a relação da aprendizagem organizacional com o processo de expatriação. Assim, o objetivo deste trabalho foi analisar a contribuição da expatriação para os processos de aprendizagem organizacional, tanto formais quanto informais, através de um estudo de casos múltiplos em empresas do sul do Brasil. Ressalta-se que a expressão "aprendizagem organizacional" aqui considerada se refere àquela no contexto organizacional.

O crescente movimento de globalização, fusões, aquisições, alianças estratégicas de empresas transnacionais e multinacionais tende a ocasionar um aumento no número de executivos expatriados. De acordo com o ranking da Fundação Dom Cabral das Multinacionais Brasileiras, dados de 2016, essas empresas continuam em uma tendência de aumento do índice médio de internacionalização, fato que indica uma tendência de expatriação também ascendente Fundação Dom Cabral [FDC] (2017). Assim, são necessários estudos que envolvam expatriação de indivíduos e estratégias de gestão internacional (Gallon \& Antunes, 2015; Silbiger, Berger, Barnes, \& Renwick, 2017), assim como sua associação com aprendizagem, desenvolvimento de pessoas e transferência de conhecimento (Bonache, Brewser, \& Suutari, 2001; Selmer \& Suutari, 2011; Gallon \& Scheffer, 2015), particularmente em empresas oriundas de economias em desenvolvimento, de forma a relacionar resultados de outros estudos (Silbiger et al., 2017)

Este artigo está dividido em cinco seções. Na primeira seção encontra-se a introdução; na segunda, a revisão teórica; a terceira refere-se ao método utilizado. A apresentação e a análise dos resultados estão relacionadas na quarta seção e, por fim, na quinta encontram-se as considerações finais. 


\section{Referencial Teórico}

$\mathrm{Na}$ seção a seguir serão abordados os temas Aprendizagem Organizacional, Expatriação e a relação entre ambos os conceitos.

\section{Aprendizagem Organizacional (AO)}

Ao retratarem a aprendizagem organizacional, Weick e Westley (2004) colocam-na em suas formas verbais "aprender" e "organizar" como um oximoro, no qual aprender traz uma conotação desorganizada, um conceito caótico, enquanto organizar possui sentido estruturado. $\mathrm{O}$ ato de organizar dependerá da imagem que cada pessoa obtiver do sistema mais amplo da organização (instituição) (Schön, 1983). Com isso, os autores atentam para as condições nas quais a aprendizagem ocorre nas organizações.

Ao referenciar AO, em uma perspectiva histórica, March e Olsen (1975) e Argyris e Schön (1996) tratam-na como aprendizagem individual em um contexto organizacional. March e Olsen (1975) fazem uma distinção entre a ação individual e a ação organizacional. Em síntese, a aprendizagem individual corresponderia à aprendizagem organizacional (Prange, 2001). No entanto, a aprendizagem organizacional é mais complexa do que uma simples ampliação da aprendizagem individual (Kim, 1998).

A AO pode ser concebida como possuidora de três subprocessos: criação, manutenção e transferência de conhecimento. Quando os indivíduos aprendem com as experiências, o conhecimento novo é criado na organização. O conhecimento pode ser retido e transferido dentro e entre as unidades. Através de transferência de conhecimento, uma unidade é afetada pela experiência de outra ou indiretamente aprende a partir da experiência dessas outras unidades (Easterby-Smith \& Araujo, 2001; Argote, 2011). Desta maneira, as organizações podem aprimorar seus desempenhos a partir dos indivíduos que conseguem perceber o que ocorre no ato de evidenciar uma experiência contínua (Weick \& Westley, 2004).

No entanto, embora o indivíduo seja o agente do processo e sujeito do ato de aprender, o conteúdo e o contexto da aprendizagem referem-se ao ambiente coletivo. No contexto organizacional, a gestão do conteúdo de aprendizagem, a acumulação de informações, conhecimento adquirido e utilização e transferência interna desse conhecimento são os mecanismos que explicam como a aprendizagem acontece (Nogueira \& Odelius, 2015).

A aprendizagem ocorre nas interações sociais dos indivíduos e não somente em suas mentes. Isso remete a um fenômeno cultural e social, não somente cognitivo (Nicolini, Gherardi, \& Yanow, 2003; Gherardi, 2005; Antonello \& Godoy, 2010). Antonello e Godoy (2010) relatam, ao falar sobre a aprendizagem organizacional através de uma abordagem social, que toda a atividade na vida dos indivíduos é uma oportunidade para aprendizagem. Além disso, os autores reiteram que aprender em situações casuais é tão importante quanto aprender através de processos formais 
de aprendizagem, em um contexto de divisões do trabalho e relações de poder, ambiente, cultura e linguagem.

Para Kim (1998), os indivíduos que são oportunizados a aprender, ao vivenciarem eventos concretos do cotidiano e observarem ativamente o que acontece, avaliam sua experiência pela reflexão sobre suas observações e então projetam ou constroem um conceito de aprendizagem. Nesse contexto, a aprendizagem não abarca somente ações e atividades, mas também o papel da linguagem e outros artefatos culturais e materiais, assim como a natureza das interações sociais e as respostas tácitas dos indivíduos (Gherardi \& Nicolini, 2001). Assim, o que as pessoas aprendem são significados intersubjetivos inseridos na cultura (Weick \& Westley, 2004; Antonello, 2011).

Aprendizagem depende não somente de sistemas formais, que envolvem treinamento ou uso de banco de dados, mas principalmente da participação no trabalho, de maneira não intencional e não deliberada (Nicolini et al., 2003; Antonello, 2011). Isso inclui situações do cotidiano capazes de tornarem-se veículos para o desenvolvimento da aprendizagem, mesmo quando em contextos formais (Antonello \& Godoy, 2010). Para Malcolm, Hodkonson e Colley (2003), existem elementos de aprendizagem formal em situações informais e elementos informais de aprendizagem em situações de aprendizagem formal. A natureza dessa inter-relação conecta-se aos contextos organizacionais, sociais, culturais, econômicos, históricos e políticos. A aprendizagem informal envolve a busca de entendimento, conhecimento ou habilidade que acontece fora dos currículos, que constituem cursos e programas educacionais, ocorrendo através de práticas presentes no cotidiano dos indivíduos, com conhecimento horizontal e também em espaços não educacionais (Malcolm, Hodkonson, \& Colley, 2003).

No estudo de Antonello (2011), que objetivava analisar o processo de intercâmbio entre as práticas informais e formais de aprendizagem, foram sugeridos doze tipos de formas de aprendizagem, categorias utilizadas também nesse trabalho: experiência anterior e transferência extraprofissional, experienciar, reflexão, autoanálise, observação/modelos, mudança de perspectiva, mentoria (mentoring) e tutoria (coaching), interação e colaboração, cursos e treinamentos, informal e aprendizagem pela articulação entre teoria e prática (Figura 1).

Importante destacar que os processos e formas de aprendizagem envolvem tanto aspectos, situações e abordagens formais e informais, assim como interagem com níveis individuais, grupais, organizacionais e interorganizacionais: aprendizagem é um fenômeno multinível (Antonello, 2011; Antonello \& Godoy, 2010; Coelho \& Mourão, 2011; Nogueira \& Odelius, 2015). Ademais, processos e níveis de aprendizagem podem interagir com os contextos nos quais se encontram, os quais podem ser tanto temporais (relacionados ao passado, presente e futuro) quanto espaciais (no que tange aos espaços intraorganizacionais e interorganizacionais) (Larentis, Antonello, Milan, \& De Toni, 2014; Nonaka, Toyama, \& Hirata, 2011). 


\section{Categorias}

Experiência anterior e transferência extraprofissional

Reflexão

Autoanálise

Observação/Modelos

Feedback

Mudança de perspectiva

Mentoria (mentoring)/ Tutoria (coaching)

Interação e colaboração

Cursos e treinamentos

Informal

Aprendizagem pela articulação entre teoria e prática

\section{Subcategorias}

Transferência de aprendizagem de ocupação/cargo anterior.

Aprendizagem oriunda da educação formal anterior.

Aprendizagem fora do trabalho.

Desenvolvimento de novas ideias ou abordagens.

Situações difíceis.

Mudanças organizacionais.

Reflexão sobre a ação e na ação.

Reflexão em grupo/coletiva.

Refletir sobre como os outros fazem as coisas.

Aprendizado oriundo do fracasso.

Autoanálise e autoavaliação.

Observação estruturada e crítica ou informal dos outros.

Modelo positivos ou negativos.

Feedback oriundo da equipe de trabalho ou de clientes.

Avaliação de desempenho

Leitura da linguagem do corpo.

Mudança de papel.

Transferência de trabalho.

Trabalhar com pessoas de áreas diferentes da sua ou outras culturas.

Assistência de um mentor.

Exercer o papel de mentor.

Trabalho em equipes multidisciplinares.

Aprendizagem oriunda de outros profissionais da mesma área ou de clientes.

Networking.

Treinamento no trabalho.

Multiplicação de treinamentos.

Informal no trabalho: baseada na prática.

Informal: em cursos de mestrado e especialização.

Trabalhos e pesquisas durante cursos.

Especialização articulada à aprendizagem baseada no trabalho.

Figura 1. Formas de Aprendizagem.

Fonte: Adaptado de Antonello (2011).

\section{Expatriação}

A crescente concorrência global provocou a necessidade da área de gestão de pessoas das organizações desenvolverem sistemas e políticas que promovam e utilizem a competência dos indivíduos (Adler \& Bartholomew, 1992) para o desenvolvimento de estratégias internacionais das organizações. Para Freitas (2010), essas estratégias consistem em: i) internacionalização 
da gestão da empresa, ii) aumento do repertório de conhecimentos para desenvolver um projeto ou uma unidade específica, iii) formação de novos líderes, iv) elevação do nível de coordenação de unidades geograficamente dispersas, v) elevação da diversidade estratégica de seus recursos humanos face a mercados globais e vi) exemplificação de aspectos importantes da cultura da empresa mãe.

Para Cavusgil et al. (2010), os gestores das empresas possuem a responsabilidade de aprimorar suas estratégias de internacionalização para transformar suas organizações em empreendimentos globalmente competitivos. Para poder aprimorar as estratégias de internacionalização, a empresa pode contar com a decisão de expatriar empregados. Todavia, isso não significa que tal decisão seja tomada apenas pela empresa: envolve também os indivíduos, os quais avaliam ganhos em relação a suas carreiras, expectativas futuras de ascensão a cargos e, quando cabível, a oportunidade de oferecer aos filhos uma melhor educação e a aquisição de novo idioma e habilidades interculturais (Freitas, 2010).

As transferências de expatriados podem ser tratadas como uma ferramenta estratégica no desenvolvimento de habilidades de negócios globais dentro da gestão de uma empresa. A estratégia da empresa define o objetivo e o modelo de expatriação e, consequentemente, o perfil do expatriado. A expatriação pode, portanto, ser entendida como uma estratégia de gestão de pessoas que visa tanto desenvolver internacionalmente a organização, como as competências do executivo global (Gallon \& Antunes, 2013; 2015). Ademais, pode ainda ser percebida como uma estratégia de controle direto e de coordenação informal através da socialização e a construção de redes de comunicação informal (Harzing, 2001).

Para Whitehead (2017), os expatriados podem ser considerados como uma categoria particular de profissionais com habilidades diferentes, realocados internacionalmente, os quais pretendem continuar a mover-se globalmente para obter ainda maiores crescimentos pessoais e profissionais. Com relação à legislação, entende-se que o conceito de expatriação também pode variar de acordo com cada país. No Brasil, conforme a Lei n. 11.962, os empregados tornam-se expatriados perante a lei após 90 dias de trabalho no país estrangeiro. Isso implica o recebimento de benefícios e remuneração como expatriado somente após esse período (Brasil, 2017; Gallon \& Antunes, 2013).

Nesse caso, a presença do expatriado é mais efetiva em facilitar controle informal, através da socialização e comunicação em subsidiárias mais independentes da matriz, enquanto nas mais dependentes a presença serve para facilitar o controle direto (Harzing, 2001). Destaca-se também que indivíduos em subsidiárias em crescimento podem servir para ampliar a sua visibilidade em relação à empresa-matriz, ajudando a consolidar ou modificar suas estruturas de atenção (Plourde, Parker, \& Schaan, 2014).

Em uma pesquisa realizada por Tanure et al. (2007), os resultados apontaram que o principal motivo da expatriação é a necessidade de controlar subsidiárias por meio de pessoas de confiança, ou seja, um olhar nacional no exterior. Freitas (2010) especifica que as necessidades mais comuns são relacionadas à necessidade de complementar os conhecimentos da equipe 
de execução de novos projetos, gestão da inovação e controle ou reforço da cultura organizacional. Em relação a isso, uma estratégia de expatriação deve compreender a maneira como serão alinhadas as atividades das subsidiárias com as metas estratégicas da matriz além das suas fronteiras nacionais, pelo nível de incerteza presente (Gong, 2003).

Gallon e Antunes (2013; 2015) também mencionam a expatriação como sendo constituída por três momentos que interagem entre si e devem fazem parte da estratégia organizacional. Além disso, deve-se entendê-la como parte do processo de internacionalização da organização e não somente como mais uma prática da gestão de pessoas. Essas três fases são: (1) a preparação para a missão, (2) a missão em si (expatriação) e (3) a volta da missão (repatriação).

A preparação envolve clareza dos objetivos da expatriação na estratégia, recrutamento e seleção dos candidatos à expatriação, preparação cultural e técnica do expatriado, orientação ao expatriado em relação à gestão de carreira e remuneração e, por fim, orientação à família do expatriado. Na expatriação em si ocorre a adaptação do expatriado e da família ao novo país, o que envolve os auxílios e suporte da empresa com enfoque pessoal, profissional e a preparação do expatriado para repatriar. A repatriação é mais do que o simples fato de retornar ao país de origem, pois abrange atividades de readaptação ao novo cotidiano, afinal, tanto o expatriado como a organização sofreram mudanças (Gallon \& Antunes, 2015).

Ainda sobre essas fases, tem-se resultados de estudos que expatriados que se movem a determinado país em função do país que em função do trabalho podem estar mais preparados para desafios interculturais que para os associados a iniciar um novo trabalho no exterior (Howe-Walsh \& Schyns, 2010). Por outro lado, a adaptação na expatriação no plano pessoal, profissional e familiar é favorecida pela proximidade cultural, domínio do idioma do país anfitrião, relacionamentos fora do trabalho, disposição ao risco, flexibilidade, capacidade técnica, perspectiva de crescimento profissional e mudança da dinâmica familiar (Vianna \& Souza, 2009). No entanto, no momento de repatriação pode haver frustação devido à redução de responsabilidades, de autonomia e de desafios naqueles casos que voltaram a exercer as mesmas atividades antes da expatriação (Gallon \& Scheffer, 2015).

As expatriações englobam as exigências do mercado de trabalho atual e tendem a gerar, nos executivos, experiências que afetam suas expectativas pessoais e profissionais (Homem \& Dellagnelo, 2006). Esse é um dos motivos pelos quais os expatriados passam a valorizar mais sua experiência internacional e percebem que os aspectos financeiros não são tão importantes frente ao aprendizado adquirido. Por isso, a prática de gestão de desempenho dos expatriados é uma importante análise na gestão internacional. Ainda no contexto de organizações modernas, o discurso da transferência dos indivíduos permeia questões de deslocamento e local versus global. Entretanto, este assunto de pensar global e agir local influencia a forma com a qual indivíduos expatriados relacionam sua realidade com outras culturas completamente diferentes (Whitehead, 2017). 
Leva-se em conta que a expatriação pode ser encarada como uma oportunidade de amadurecimento para o indivíduo, tendo em vista a integração das experiências, trajetórias e referências passadas com o presente (Cerdin \& Dubouloy, 2004). Tal experiência é reconhecida no mercado de trabalho, abrindo possibilidades novas de recolocação, o que faz com que os repatriados deem mais valor à sua carreira interna (conjunto de experiências e aprendizados vivenciados pelo indivíduo) do que à carreira organizacional (ocupações e cargos dentro da empresa (Gallon \& Scheffer, 2015). Por essa razão, a expatriação teve maior impacto nas carreiras daqueles que já haviam experienciado expatriações como uma atividade de desenvolvimento de habilidades (Ramaswami, Carter, \& Dreher, 2016).

A especificidade da expatriação decorre de um conjunto de aspectos específicos, destacando-se uma noção de duração (finita) e um sentido de persistência da integração na organização em um momento posterior à mobilidade internacional (Coelho, 2017), uma vez que há a necessidade de mobilização intelectual e afetiva dos indivíduos a novas situações (Prestes, Grisci, \& Fraga, 2016). Desta forma, para o sucesso de uma expatriação, Certo (2003) e Ramaswani et al. (2016) destacam a importância do treinamento dos empregados a expatriar, como forma de qualificação e reflexão a respeito de conhecimentos, habilidades e atitudes. Assim, torna-se fundamental um treinamento prévio, seja ele cultural ou de línguas estrangeiras (Sebben \& Dourado, 2010). O fator que mais contribui para que esses treinamentos sejam ministrados ao expatriado e, muitas vezes, a suas famílias, é a volta precoce que ocorre com frequência pelas empresas não saberem das reais necessidades locais (Cateora \& Graham, 2009).

Nesse contexto, muitas das funções de gestão de pessoas, como movimentação, desenvolvimento e valorização de pessoas tornam-se mais complexas quando uma dimensão da expatriação é incluída (Harzing, 2001). No entanto, evidências empíricas reforçam que as empresas necessitam dar mais atenção a isso. Falta uma clara conexão entre a estratégia de internacionalização da empresa e os processos de expatriação em organizações brasileiras (Vianna \& Souza, 2009), principalmente pela informalidade de suas práticas (Gallon \& Antunes, 2013). Além disso, o papel da gestão de pessoas no processo de expatriação está muito mais associado a tramitações burocráticas do que a aspectos como desenvolvimento de pessoal, gestão de carreira, avaliação de desempenho e acompanhamento do profissional. Logo, os expatriados partem como a solução do problema, mas podem voltar como o problema (Gallon \& Bitencourt, 2016). Além disso, empresas que não possuem políticas e práticas para dar suporte à repatriação apresentarão maiores dificuldades em reter o empregado, desperdiçando investimentos em capital humano e financeiro (Gallon \& Antunes, 2015).

\section{Relação entre Expatriação e Processos de Aprendizagem}

O entendimento da relação entre expatriação e processos de aprendizagem é fundamental para a aquisição de vantagem competitiva das organizações. Nesse sentido, Barakat e Moussa (2014) afirmam que é imperativo estudar os fatores que influenciam os processos de aprendizagem. 
A expatriação, por sua vez, em contexto de internacionalização de empresas, pode delimitar oportunidades de aprendizagem e, simultaneamente, o questionamento de relações de pertença pré-existentes (Coelho, 2017).

Em relação a isso, Moreira, Norões e Ogasavara (2014) analisam a estratégia da expatriação em três âmbitos: do expatriado, da empresa e do ambiente internacional. Em cada um desses âmbitos, ainda deve ser analisado o processo de aprendizagem que o expatriado desenvolve em seu período de (i) expatriação, em seu período (ii) anterior à expatriação - de preparo e treinamento - e em seu período (iii) pós expatriação, ou repatriação.

Além disso, de acordo com De Clercq, Sapienza e Crijns (2005), quanto mais conhecimento a empresa ganha através de esforços de aprendizagem, mais disposta ela estará para usar e explorar esses conhecimentos através das atividades internacionais subsequentes. Para os autores, a renovação do conhecimento nas organizações e a utilização (exploitation) de estratégias em mercados estrangeiros afetam as percepções de oportunidades oferecidas por uma maior expansão internacional. Nesse ínterim, estudo de Bonache et al. (2001) identificaram que grande parte do conhecimento transferido entre unidades na expatriação foi tácito, não explícito. Tal conhecimento está incorporado na experiência e nas habilidades dos indivíduos e somente pode ser revelado através da sua aplicação. Expatriação é, portanto, segundo os autores, mecanismo básico para transferir conhecimento tácito.

Para Niessen, Sonnentag e Sach (2012), quanto maior o nível de vida social, quanto mais as necessidades de parentesco, afetividade e valorização forem oportunizadas pela organização ao indivíduo expatriado, maiores são as tendências de desenvolverem um sentimento afetivo e cognitivo da aprendizagem. No entanto, uma vez que os expatriados veem suas missões internacionais como uma oportunidade para promover benefícios intrínsecos, tais como autonomia, competência e desenvolvimento da própria família, ao perceberem que esses benefícios não estão sendo levados em consideração pelas organizações, a aprendizagem no local de trabalho será prejudicada (Ren, Yunlu, Shaffer, \& Fodchuk 2015).

Por outro lado, quando expatriados experienciam a aprendizagem proveniente de suas atribuições, eles tornam-se mais propensos a ter a energia e a motivação para manterem-se engajados no trabalho (Porath et al., 2011). Portanto, os expatriados que percebem o lado afetivo e cognitivo da aprendizagem tendem a estar mais preparados e dispostos, o que ajuda a explicar a retenção em suas atribuições (Ren et al., 2015).

Nesse ínterim, Gonzalez e Chakraborty (2014) descrevem as características individuais dos expatriados (competências relacionadas com a tarefa intercultural, motivação para transferência de conhecimento e ajustes necessários para a missão internacional), bem como as características necessárias das subsidiárias no exterior (em relação à eficácia da transferência de conhecimento, ou seja, na capacidade de absorção desse conhecimento). Para os autores, o conhecimento que flui ciclicamente do indivíduo para a organização não precisa acontecer necessariamente e apenas no momento da repatriação ou volta dos expatriados aos países de 
origem, mas durante a expatriação, de forma contínua. Quanto a isso, estudo de Gallon e Scheffer (2015) apontou que o que mais impacta na relação entre carreira e expatriação é a aprendizagem adquirida, tanto em termos pessoais como profissionais, envolvendo maior capacidade para tomada de decisão, mudança de perspectiva e melhor compreensão dos limites, ou ainda, como síntese, a aprendizagem de vida.

A partir disso, Barakat e Moussa (2014) exploram, em seu trabalho, que existem variáveis individuais e situacionais que influenciam a relação entre as missões internacionais e a aprendizagem dos expatriados, sendo: disposição dos indivíduos para adquirir conhecimentos e habilidades e aprender a partir dos outros; sua inteligência e distância cultural; preparação dos trabalhadores para uma missão internacional; avaliação de desempenho de um expatriado no país hospedeiro; definição do perfil do escritório ou empresa internacional e a seleção de pessoas para trabalhar com o expatriado. Nesse aspecto, no estudo de Gallon e Bittencourt (2016), afirma-se que a expatriação adquiriu significado de reconhecimento e de valorização, tanto da empresa quanto dos colegas de trabalho, em que o repatriado era percebido como uma pessoa mais experiente e com maior conhecimento. Em pesquisa de González e Oliveira (2011), expatriados observaram transformações na sua identidade e autoconceito vinculadas à experiência da expatriação.

\section{Procedimentos Metodológicos}

A pesquisa, qualitativa, exploratória e descritiva, deu-se através de um estudo de casos múltiplos. O estudo de casos múltiplos é indicado quando as provas conclusivas são consideradas mais convincentes e o estudo global é visto como mais robusto (Yin, 2010).

A utilização de fontes de evidências diferentes é o desenvolvimento de um processo de triangulação dos dados, promovendo, assim, a qualidade da pesquisa qualitativa (Flick, 2009; Yin, 2010). Este estudo averiguou e confrontou as informações na triangulação de dados através de: (i) entrevistas em profundidade com empregados expatriados, (ii) observação direta e (iii) análise de documentos, a fim de tornar mais evidentes os dados analisados.

A Tabela 1 apresenta a quantidade de empregados expatriados entrevistados por empresa, o tempo que os mesmos permaneceram expatriados ou que estão em processo de expatriação, o país de expatriação e o ano em que ocorreu a expatriação. Ressalta-se que todos os entrevistados desempenhavam o papel de gestores de exportação previamente à expatriação, e que ficaram responsáveis pela gestão das unidades subsidiárias.

Conforme pode ser visto na Tabela 1, para a seleção dos expatriados que foram entrevistados em cada organização, adotaram-se critérios a fim de diferenciar o perfil dos respondentes. A seleção deu-se através dos seguintes critérios:

a. gênero: mesclar a quantidade de respondentes do sexo feminino e masculino, na medida do possível, visto que foram encontrados mais expatriados do sexo masculino; 
b. período de expatriação: buscaram-se respondentes com diferentes tempos de permanência no país estrangeiro;

c. ano de expatriação: o ano de expatriação é um critério bem variado entre as organizações, pois algumas possuem unidades de negócio no exterior há bastante tempo;

d. país de expatriação: buscaram-se respondentes que foram expatriados para localidades diferentes em uma mesma organização. Na empresa D esse critério não ocorreu, pois todos os empregados foram expatriados para o mesmo país devido à empresa possuir unidade de negócio apenas na Guatemala no momento atual.

Tabela 1. Relação de empregados expatriados entrevistados na pesquisa e critérios para seleção

\begin{tabular}{|c|c|c|c|c|c|}
\hline Empresa & $\begin{array}{l}\text { Funcionários } \\
\text { Expatriados }\end{array}$ & Sexo & $\begin{array}{l}\text { Período de } \\
\text { Expatriação }\end{array}$ & $\begin{array}{c}\text { Ano da } \\
\text { Expatriação }\end{array}$ & País de Expatriação \\
\hline \multirow{3}{*}{$A$} & Entrevistado 1 & Masculino & 3 anos & 2000 & Índia \\
\hline & Entrevistado 2 & Masculino & 4 anos e 6 meses & 2004 & Colômbia \\
\hline & Entrevistado 3 & Masculino & 2 anos & 2011 & Índia \\
\hline \multirow{2}{*}{ B } & Entrevistado 4 & Masculino & 10 anos & 2005 & Emirados Árabes Unidos \\
\hline & Entrevistado 5 & Masculino & 1 ano & 2014 & África do Sul \\
\hline C & Entrevistado 6 & Masculino & 1 ano & 1999 e 2001 & Colômbia e Chile \\
\hline \multirow{4}{*}{$\mathrm{D}$} & Entrevistado 7 & Masculino & 8 meses & 2008 & Guatemala \\
\hline & Entrevistado 8 & Masculino & 3 anos & 2009 & Guatemala \\
\hline & Entrevistado 9 & Masculino & 4 anos e 5 meses & 2010 & Guatemala \\
\hline & Entrevistado 10 & Masculino & 3 anos e 8 meses & 2011 & Guatemala \\
\hline \multirow{2}{*}{$E$} & Entrevistado 11 & Feminino & 2 anos e 6 meses & 2002 e 2004 & México, EUA e Bharein \\
\hline & Entrevistado 12 & Feminino & 2 anos e 8 meses & 2003 e 2014 & EUA e Itália \\
\hline
\end{tabular}

Fonte: elaborado pelos autores.

Os casos estão representados por cinco empresas com sede na região da Serra Gaúcha que possuem subsidiárias no exterior: três do ramo metalmecânico ( $A, B$ e C), uma do ramo moveleiro (D) e uma do ramo calçadista (E), com exportação ocorrendo no Ceará. Yin (2010) considera fundamental a definição da unidade de análise do estudo. Ou seja, o que será o caso propriamente dito, ou os casos, quando se fala de estudos de casos múltiplos. Tal afirmação vem ao encontro do trabalho de Eisenhardt (1989), ao discutir o uso de casos para a construção de teorias. De acordo com a autora, a construção de teorias a partir de casos é um processo, no qual a primeira etapa é marcada pela seleção dos casos. Para Eisenhardt (1989), na seleção de casos, a riqueza de detalhes permite ao pesquisador explorá-los na construção da teoria. Além disso, afirma que não existe um número ideal de casos, mas que de quatro a dez são adequados para esse método.

Para a realização da pesquisa proposta, as unidades de análise estão representadas por cinco empresas da região da Serra Gaúcha que possuem subsidiárias no exterior. Por possuírem negócios no exterior, essas empresas 
optaram por expatriar seus empregados. A justificativa para a seleção dessas empresas centra-se na importância delas para a atividade exportadora dos estados nas quais exportam. As empresas A e B classificam-se dentre as 50 principais exportadoras do Rio Grande do Sul, a C dentre as 150 e a D dentre as 200. Por fim, a empresa E classifica-se dentre as 50 principais empresas exportadores do Ceará (Brasil, 2016). Cabe salientar que a empresa E, situada no município de Farroupilha, possui uma unidade fabril instalada em Sobral, no estado do Ceará, responsável pela maior parte do escoamento das suas exportações. Ademais, a empresa A está entre as 10 primeiras colocadas no ranking da Fundação Dom Cabral de 2015 das empresas com maior índice de colaboradores que desempenham suas funções a partir de subsidiárias comerciais e/ou produtivas no exterior (FDC, 2016).

Com relação às entrevistas, elaborou-se uma proposta de roteiro semiestruturado de questões que deram suporte à coleta de dados. Os temas contemplados nas questões basearam-se nas categorias de Antonello (2011), apresentadas no Referencial Teórico. As entrevistas foram gravadas e posteriormente transcritas pelo pesquisador. Elas tiveram um tempo médio de duração de 49 minutos, sendo 1 h e 05 minutos a mais longa e 43 minutos a mais curta.

Também foram feitas visitas prévias às entrevistas nas empresas $A, B$ e D, a fim de coletar materiais institucionais e observar o dia a dia delas, mais especificamente os setores de Exportação, Importação e Recursos Humanos. Além disso, somente na empresa D houve a autorização para participar em três reuniões relacionadas aos projetos das subsidiárias no exterior.

Quanto à análise documental, buscaram-se documentos das empresas para conhecer seu histórico, unidades e produtos; entender a importância das exportações para o faturamento; identificar gastos com folhas de pagamentos; visualizar como ocorrem as negociações internacionais das empresas e a comunicação entre empresa e seus stakeholders; identificar como ocorrem o planejamento das ações de internacionalização, preparo de empregados para o exterior e comunicação da empresa para com seu público-alvo no exterior.

Nesta pesquisa foi utilizada a análise de conteúdo como técnica de análise de dados (Bardin, 2011; Vergara, 2005). Os procedimentos sistemáticos da análise do conteúdo das mensagens das entrevistas deram-se através da sistematização da leitura das transcrições, além de atitude interpretativa (Bardin, 2011). Primeiramente, ocorre uma análise temática, na qual se divide o texto em temas principais, revelados pelas categorias. Em seguida, revelam-se as características associadas ao tema central, considerando extratos das falas dos entrevistados, extraindo-se seus significados. O terceiro passo é a análise sequencial, na qual são inseridas sequências, por exemplo, de introdução e fechamento do tema. Neste trabalho, a análise sequencial está representada pela introdução de questões sobre o tema e sobre a relação entre os temas aprendizagem organizacional e expatriação. Por fim, tem-se a análise da entrevista através da 'maneira de dizer' de cada entrevistado, fato que pode aprofundar a análise. 


\section{Resultados}

Primeiramente, apresentam-se as semelhanças e particularidades entre os casos tendo em vista as etapas da expatriação (preparação para a missão, missão e retorno da missão). Em seguida, analisam-se as formas de aprendizagem na expatriação. Resultante dessas seções, apresenta-se o esquema conceitual.

\section{Etapas da Expatriação}

Para Argote (2011), os indivíduos são os propulsores da aprendizagem organizacional. Os expatriados devem refinar suas próprias competências que tenham relação com as tarefas que desenvolvem no exterior, pois seu aprendizado, o valor dos seus conhecimentos adquiridos, o valor desse conhecimento para suas carreiras e para a organização podem determinar o sucesso de uma expatriação (Gonzalez \& Chakraborty, 2014).

Em relação a isso, a Figura 2 conecta as três etapas da expatriação consideradas por Antal (2001) e Gallon e Antunes (2013; 2015). As conclusões desse quadro elucidam um amadurecimento dos processos de expatriação das empresas, o quanto elas aprendem ao longo do caminho e o quanto compreendem com seus próprios erros. Nesse aspecto, até em função da confiança, tende-se a perceber que um maior tempo que o empregado trabalha na organização pode levar a empresa a investir menos em seu preparo. Empregados que possuíam mais de 10 anos de empresa receberam menor atenção em seu processo de preparação à expatriação, em comparação àqueles com 2 ou 3 anos de empresa.

Além disso, pode-se observar que a empresa A configurou seu processo de expatriação de maneira particular às demais empresas. Já as empresas $\mathrm{D}$ e $\mathrm{E}$ tiveram seus processos em formatos mais próximos. Destaca-se que as empresas B e C, por serem do mesmo grupo, também apresentaram semelhanças na etapa de preparo da missão de seus empregados. As empresas B e $\mathrm{E}$ ainda contam com empregados expatriados, por isso não foram descritas situações na etapa de retorno da missão. O relato a seguir atesta isso:

\footnotetext{
Eu tenho o caso de um colega que volta do México em março, então já definiram a pessoa que vai [...]. A gente vai ter 6 meses pra treinar essa pessoa no idioma. As duas pessoas já começam a se falar. Eles podem já antecipadamente trocar experiências e etc. O segundo é que a pessoal que volta já fica mais tranquila. Hoje é aquele negócio, a pessoa que vem já diz: eu vou voltar para a empresa, pra onde eu vou? O que eu vou fazer? Esse é o maior problema. O cara sai daqui, vai pra lá, aprende inglês, tem um crescimento brutal e volta no mesmo cargo. Então isso é coisa que a empresa tá pensando pra dar um salto. (E3 - Empresa A).
} 


\begin{tabular}{|c|c|c|c|c|}
\hline & \multicolumn{3}{|c|}{ Etapas da Expatriação } \\
\hline & & Preparação para a Missão & Missão & Retorno da Missão \\
\hline \multicolumn{2}{|c|}{$\begin{array}{l}\text { Características } \\
\text { de cada etapa } \\
\text { (Semelhanças) }\end{array}$} & $\begin{array}{l}\text { _ Possui maior relacionamento } \\
\text { com a execução de cursos } \\
\text { de línguas, sem preparo da } \\
\text { família; } \\
\text { _ } \quad \text { Pouco contato com a cultura } \\
\text { do país de destino; } \\
\text { - } \quad \text { Aprender a nova cultura e } \\
\text { saber como se comportar } \\
\text { depende da vivência do } \\
\text { expatriado e de seu interesse } \\
\text { em buscar ajuda. }\end{array}$ & $\begin{array}{l}\text { - } \text { Considera características } \\
\text { individuais do expatriado, } \\
\text { seus valores a respeito da sua } \\
\text { educação, sua formação e daquilo } \\
\text { que entende como sendo justo } \\
\text { para sua organização; } \\
\text { - } \\
\text { Andamento dependente da } \\
\text { proatividade do expatriado e do } \\
\text { respaldo recebido pela empresa } \\
\text { mãe. }\end{array}$ & $\begin{array}{l}\text { - } \quad \text { Incógnita para o expatriado, porque } \\
\text { não sabe se terá a aceitação da } \\
\text { empresa ao retornar; } \\
\text { - } \quad \text { Motivo de preocupação para a } \\
\text { organização no sentido de identificar } \\
\text { que cargo o repatriado ocupará, } \\
\text { provavelmente por estar com } \\
\text { habilidades culturais, gerenciais e } \\
\text { técnicas mais desenvolvidas; } \\
\text { - } \quad \text { Alguns expatriados sugerem que } \\
\text { cargos em nível hierárquico superior } \\
\text { deveriam ser oportunizados dentro } \\
\text { das organizações a empregados } \\
\text { já expatriados, pela maturidade e } \\
\text { autonomia maiores. }\end{array}$ \\
\hline \multirow{4}{*}{ Empresas } & $A$ & $\begin{array}{l}\text { - } \text { Existente em maior } \\
\text { proporção quando } \\
\text { comparado aos demais } \\
\text { casos; } \\
\text { - } \\
\text { Envio da família do } \\
\text { expatriado já contemplado } \\
\text { em uma expatriação. }\end{array}$ & $\begin{array}{l}\text { - Dificuldades evidenciadas pelos } \\
\text { mercados; }\end{array}$ & $\begin{array}{l}\text { - Atualmente processo sendo } \\
\text { trabalhado com antecedência de seis } \\
\text { meses, para que o empregado sinta } \\
\text { que ainda tem lugar na empresa. }\end{array}$ \\
\hline & C & $\begin{array}{l}\text { - } \text { Amadurecimento de políticas } \\
\text { de Recursos Humanos a } \\
\text { partir de } 2010 \text {. }\end{array}$ & $\begin{array}{l}\text { - } \text { Bem vista tanto pela empresa } \\
\text { quanto pelo empregado; } \\
\text { _ } \\
\text { Priorizada a abertura de novos } \\
\text { mercados em função das diversas } \\
\text { frentes de atuação da empresa. }\end{array}$ & - Empregados ainda expatriados. \\
\hline & D & \multirow[t]{2}{*}{$\begin{array}{l}\text { - Menores graus de preparo } \\
\text { do indivíduo à expatriação, } \\
\text { quando comparados aos } \\
\text { outros casos. }\end{array}$} & $\begin{array}{l}\text { - Positivo para o empregado em } \\
\text { adquirir novos conhecimentos; } \\
\text { - } \text { Dificuldade do mercado e } \\
\text { periculosidade do local para um } \\
\text { estrangeiro. }\end{array}$ & $\begin{array}{l}\text { - Sentimento que a empresa valoriza } \\
\text { o empregado e sua experiência na } \\
\text { expatriação. }\end{array}$ \\
\hline & E & & 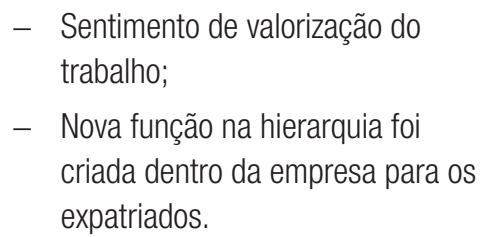 & - Empregados ainda expatriados. \\
\hline
\end{tabular}

Figura 2. Etapas da expatriação.

Fonte: elaborada pelos autores

Em tais resultados, ficam evidentes as dificuldades associadas à falta de políticas e práticas mais consistentes de gestão de pessoas no enfoque internacional (Vianna \& Souza, 2009; Gallon \& Antunes, 2013; 2015; Gallon 
\& Bittencourt, 2016), apesar do crescimento pessoal e profissional dos expatriados na interação com outras culturas e situações, tendo em vista a construção de suas carreiras (Homem \& Dellagnelo, 2006; Howe-Walsh \& Schyns, 2010; Gallon \& Scheffer, 2015; Whitehead, 2017). Além disso, nota-se as preocupações tanto dos expatriados quanto das empresas em relação à repatriação (Gallon \& Antunes, 2015; Gallon \& Scheffer, 2015).

\section{Formas de Aprendizagem na Expatriação}

Semelhanças e particularidades entre as organizações investigadas são apresentadas na Figura 3, conforme as formas de aprendizagem propostas por Antonello (2011):

\begin{tabular}{|c|c|c|}
\hline Categorias & Semelhanças & Peculiaridades \\
\hline Reflexão & $\begin{array}{l}\text { - } \text { Extrema dificuldade } \\
\text { - Pensamento e análise da situação; } \\
\text { - Dificuldades no início da carreira no país estrangeiro; } \\
\text { - Dividir medos com colegas. }\end{array}$ & $\begin{array}{ll}\text { - } & \text { Citação de algo negativo (E); } \\
\text { - } & \text { Conversar fora do trabalho (D) } \\
\text { - } & \text { Momento de dificuldade antes da } \\
& \text { expatriação (A, B e C). }\end{array}$ \\
\hline Autoanálise & $\begin{array}{l}\text { - } \text { Ter que trabalhar com áreas desconhecidas: receio } \\
\text { inicial e busca de aprendizagem; } \\
\text { - } \text { Perfil pessoal. }\end{array}$ & $\begin{array}{l}\text { - } \quad \text { Frentes de atuação de um profissional de } \\
\text { comércio exterior (A e E); } \\
\text { - } \quad \text { Nível hierárquico da empresa (D). }\end{array}$ \\
\hline Observação/Modelos & 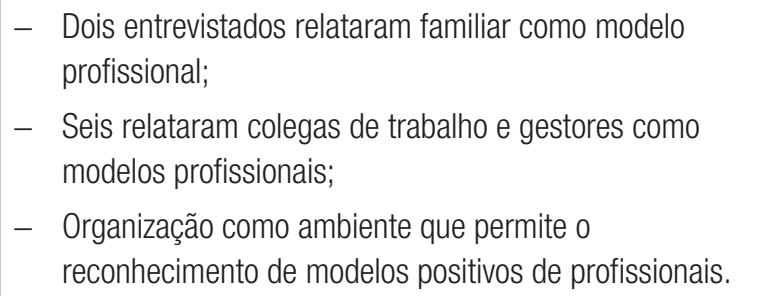 & 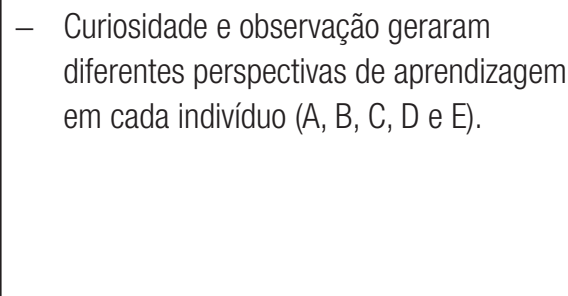 \\
\hline Feedback & $\begin{array}{l}\text { - } \quad \text { Trazer para a empresa feedback do mercado (não } \\
\text { somente feedback de ações do trabalho); } \\
\text { - } \quad \text { Tranquilidade ao receber críticas e entender que } \\
\text { ajudam no andamento. }\end{array}$ & - Feedback no tempo certo (B e C). \\
\hline Mudança de Perspectiva & $\begin{array}{l}\text { - Vontade de trabalhar na exportação e ser expatriado; } \\
\text { _ } \text { Gostar de trabalhar com novas culturas e diferentes } \\
\text { visões de mundo; } \\
\text { _ Depois de expatriado, adquirir maior empatia. }\end{array}$ & $\begin{array}{ll}\text { - } & \text { Não imaginar que seria exposto à } \\
& \text { oportunidade de expatriação (D); } \\
\text { - } & \text { Despir-se do conceito da facilidade em } \\
& \text { trabalhar com maior apoio (B e D). }\end{array}$ \\
\hline Mentoria e Tutoria & $\begin{array}{l}\text { - Poucos com orientação de tutor ou coaching para a } \\
\text { expatriação; } \\
\text { - } \quad \text { Auxílio de colegas que já haviam passado por situações } \\
\text { semelhantes. }\end{array}$ & - Iniciativa de procurar um coaching (B). \\
\hline Interação/ Colaboração & $\begin{array}{l}\text { - } \text { Ajuda mútua; } \\
\text { _ } \quad \text { Importância da diversidade de papéis na equipe para } \\
\text { resolução de problemas. }\end{array}$ & $\begin{array}{l}\text { - Coordenar equipe grande de brasileiros } \\
\text { fora do país, exigindo coordenação dos } \\
\text { momentos de integração (A); } \\
\text { - Quantidade de nacionalidades diferentes } \\
\text { (A). }\end{array}$ \\
\hline
\end{tabular}




\begin{tabular}{|c|c|c|}
\hline Cursos/Treinamentos & 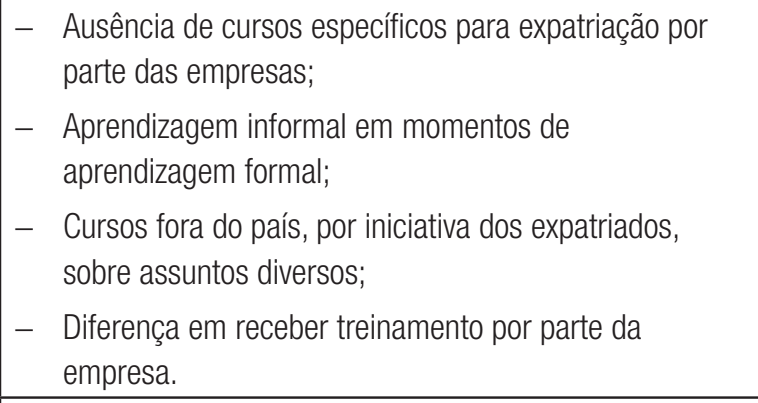 & $\begin{array}{l}\text { - } \text { Cursos executados fora do país, por } \\
\text { iniciativa dos expatriados, sobre gestão (D). }\end{array}$ \\
\hline Informal & 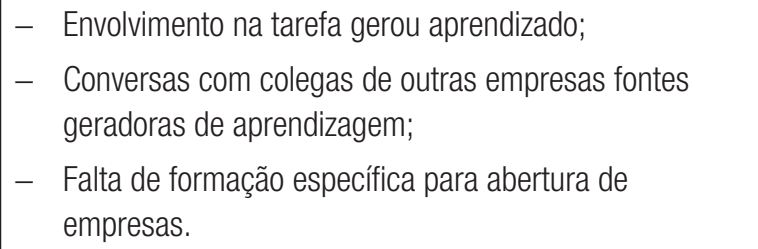 & $\begin{array}{l}\text { - Colegas de sala de aula mais experientes } \\
\text { em seus ramos de atuação (D e E). }\end{array}$ \\
\hline $\begin{array}{l}\text { Aprendizagem pela } \\
\text { Articulação entre Teoria e } \\
\text { Prática }\end{array}$ & 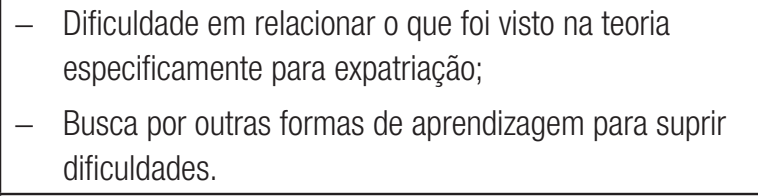 & $\begin{array}{l}\text { - } \quad \text { Networking como forma de articulação } \\
\text { entre a teoria e a prática B, C e D). }\end{array}$ \\
\hline $\begin{array}{l}\text { Experiência Anterior } \\
\text { e Transferência } \\
\text { Extraprofissional }\end{array}$ & $\begin{array}{l}\text { - Ter trabalhado em apenas uma empresa ou grupo em } \\
\text { toda carreira profissional. }\end{array}$ & $\begin{array}{l}\text { - } \text { Experiências de outras empresas no } \\
\text { âmbito internacional (A). }\end{array}$ \\
\hline Experienciar & $\begin{array}{l}\text { - Importância do planejamento individual e organizacional } \\
\text { para refletir e agir. }\end{array}$ & $\begin{array}{l}\text { - } \quad \text { Dificuldade pela crise }(D) ; \\
\text { - } \quad \text { Expatriação como fonte de aprendizado } \\
\quad \text { para a organização }(A, B, C, D \text { e E). }\end{array}$ \\
\hline $\begin{array}{l}\text { Expatriação e Resultados } \\
\text { da Aprendizagem }\end{array}$ & $\begin{array}{l}\text { - Importância para indivíduo; } \\
\text { - } \quad \text { Expatriado fundamental para ampliação de mercados; } \\
\text { - } \quad \text { Falta de preparo das organizações em entender e } \\
\text { aplicar como se expatria um empregado. }\end{array}$ & $\begin{array}{l}\text { - } \text { Empresa começa a possuir um processo } \\
\text { mais estruturado, em expatriação e } \\
\text { repatriação (A, B e C). }\end{array}$ \\
\hline
\end{tabular}

Figura 3. Formas de Aprendizagem na Expatriação.

Fonte: Elaborado pelos autores

Para os entrevistados, a expatriação é realmente vista como uma transferência de conhecimentos junto ao indivíduo, pois este será responsável por manter alguns aspectos da empresa mãe, tais como forma de negociação e relacionamento pessoal na subsidiária no exterior. Outro aspecto identificado foi o discernimento entre aprendizagem formal e informal, interpretando a aprendizagem informal como uma relação de experienciar momentos do cotidiano e a aprendizagem formal como algo institucionalizado. Segue relato que atesta isso:

Eu aprendi muito lá, foram feitos novos passos, tanto por minha parte, enfim, todas as pessoas que estiveram na empresa [...] eu acho que com a nossa aprendizagem, a oportunidade que tivemos lá, a empresa conseguiu ter um crescimento, ou seja, nossos olhos, era nossa maneira de aprender como, qual era a melhor maneira da empresa operar. (E9 - Empresa D). 
O fato de os entrevistados terem sido questionados sobre terem ou não vivenciado uma situação de extrema dificuldade na vida profissional levou-os a refletir o quanto eles aprenderam com essa experiência. Além disso, também fez refletir como transformar essa situação em algo positivo para suas carreiras e como lidar com a mesma situação ou situações parecidas em outros momentos da sua vida profissional. O processo de conhecer a si mesmo e aprender sobre si (autoanálise) também acaba por gerar uma reflexão sobre atitudes do indivíduo antes do momento da expatriação e, principalmente, durante a missão. A reflexão, por sua vez, gera uma aprendizagem e um amadurecimento necessários para enfrentar as dificuldades de estar trabalhando em um país estrangeiro, além de contribuir para analisar essa experiência positiva ou negativamente para o indivíduo e para a organização:

A gente tem que pensar, avaliar bem a situação, tem a questão da família, mas acho que dificilmente eu deixo passar uma oportunidade [...], e tem oportunidades mais fáceis de se adaptar e mais difíceis, mas normalmente a gente encara o desafio. Então como eu sempre fiz aqui na empresa, eu aceitei. (E1 - Empresa A).

Essa experiência (expatriação) foi um aprendizado, mas lá era uma outra estrutura, outra cultura de empresa, então a primeira coisa que tu aprende no exterior é conseguir se relacionar com as outras pessoas [...] que tem uma cultura de empresa e uma forma de pensar bem diferente, [...] porque depois processos e montar uma empresa, com suas burocracias e coisas não é muito difícil. (E12 - Empresa E).

O que os indivíduos entendem pelas diferenças entre aprendizagem formal e informal reforça a consciência de que a aprendizagem informal pode aumentar a aprendizagem na organização e, a partir disso, serem desenvolvidos mecanismos para facilitar esse tipo de aprendizagem nas empresas. Na experiência da expatriação, o fato de um indivíduo ser exposto ao mesmo tempo a conjuntos culturais diferentes pode representar uma ameaça para a estrutura da sua identidade pessoal. Ademais, a exposição a uma cultura estrangeira leva o indivíduo a ver a sua própria cultura sob uma nova ótica:

Ajudou, ajudou bastante (informal). Pra ser bem sincero, ajudou muito e principalmente no sentido da informação, do conhecimento informal, [...], o networking com diversos colegas, que eram todos mais velhos, diretores de empresas. O teórico ajudou muito no sentido organizacional, de $\mathrm{RH}$, de finanças de contabilidade. (E10 - Empresa D).

Imagine uma pessoa que se muda para uma metrópole com mais de 5 milhões, num país com tudo diferente: hábitos, costumes, crenças, raça. Foi uma coisa tipo "esquece tudo e começa do zero". É preciso capacidade de adaptação e visão de futuro para que tudo volte a fazer sentido novamente. Não havia mais o conforto de contar com alguém num momento de decisão, e isso acaba tornando a pessoa muito mais eficiente, por causa da independência. Porém, é preciso também assimilar que a responsabilidade também não pode mais ser compartilhada (E4 - Empresa B).

Park e Mense-Petermann (2014) reforçam o desafio da conexão do conhecimento distribuído entre as diferentes unidades da organização. Uma fonte de aprendizado proveniente de outras pessoas pode estar relacionada ao feedback recebido pelo empregado. Em relação a isso, poucas empresas demonstraram devolver ao empregado feedback em um tempo hábil de 
desenvolvimento da atividade. Vale ressaltar que poucas trabalharam com grandes equipes no exterior. Expatriados que estudaram no país sede da subsidiária voltaram com relações de networking provenientes da aprendizagem formal e informal mais desenvolvidas, pois tiveram contato com pessoas e gerentes de outras organizações, além de contato com outros expatriados de diferentes localidades que proporcionaram uma riqueza de informações nos encontros e nas trocas de informação.

Por fim, as organizações tendem a enxergar o tempo de trabalho e os setores em que o indivíduo trabalha e/ou trabalhou como uma forma de preparo para a expatriação, pois quanto mais tempo de casa o empregado possui, mais ele conhece e entende da empresa e, consequentemente, mais vai conseguir levar da empresa para o exterior, em termos de valores, cultura e formas de trabalhar. Ainda assim, Howe-Walsh e Schyns (2010) indicam que expatriados mais preparados em função do país que em função do trabalho podem estar mais capacitados para desafios interculturais. Ademais, as famílias praticamente não foram mencionadas pelos entrevistados nos seus momentos de preparo, mesmo quando instigados para tal.

\section{Esquema Conceitual}

A partir desses resultados, foi elaborado um esquema conceitual (Figura 4). As linhas horizontais representam os limites do país onde a empresa mãe está sediada e as linhas verticais representam uma separação entre as fases da expatriação, consideradas por Antal (2001) como o preparo para a missão, a missão em si e o retorno da missão. Em ambos os sentidos, as linhas são tracejadas de maneira a representar o fluxo de conhecimento e informações que perpassam entre as fases, bem como o fluxo de informação e conhecimento que transita entre o indivíduo, a empresa mãe e a subsidiária no exterior. A representação da aprendizagem em seta dupla indica relação da empresa mãe para a subsidiária e viceversa, através dos indivíduos.

Algumas características são salientadas em pontos específicos do esquema conceitual. Com relação à empresa mãe, notou-se que as políticas de gestão de pessoas ainda não contemplam os processos de expatriação das organizações pesquisadas. Também se percebeu que as interações e a colaboração entre os colegas ocorrem de maneira mais intensa, propiciando formulação de estratégias mais consolidadas. Há o reconhecimento de uma deficiência no oferecimento de cursos e treinamentos relativos à expatriação por parte das empresas. Além disso, a expatriação proporcionou uma melhora no relacionamento dos empregados, ou seja, a partir de uma situação externa, a empresa mãe obteve um ganho na qualidade do relacionamento de seus empregados.

Quanto à empresa subsidiária no exterior, identificou-se nos casos investigados que os expatriados foram os principais responsáveis por sua organização e estruturação de processos. Isso se justifica também pela falta de preparo da empresa nos aspectos atinentes à gestão internacional de pessoas, que acaba deixando o processo sob a responsabilidade do expatriado. A empresa é vista como uma fonte de oportunidade para o 
empregado expatriado, por oportunizar um ganho considerável tanto pessoal quanto profissional. Outrossim, a confiança depositada pelas empresas nos empregados expatriados repercute naquilo que eles devolvem enquanto desenvolvimento do seu trabalho, de condução e abertura de novos mercados, não somente no país onde está a sede da unidade no exterior, mas países próximos, que podem ser atendidos através da subsidiária. Tais resultados remetem às implicações de uma atenção reduzida pelas empresas quanto à gestão de pessoas no âmbito das expatriações (Vianna \& Souza, 2009; Gallon \& Antunes, 2013; 2015; Gallon \& Bittencourt, 2016) e seus efeitos na aprendizagem e na geração de conhecimento às organizações / (Ren et al., 2015; Coelho, 2017).

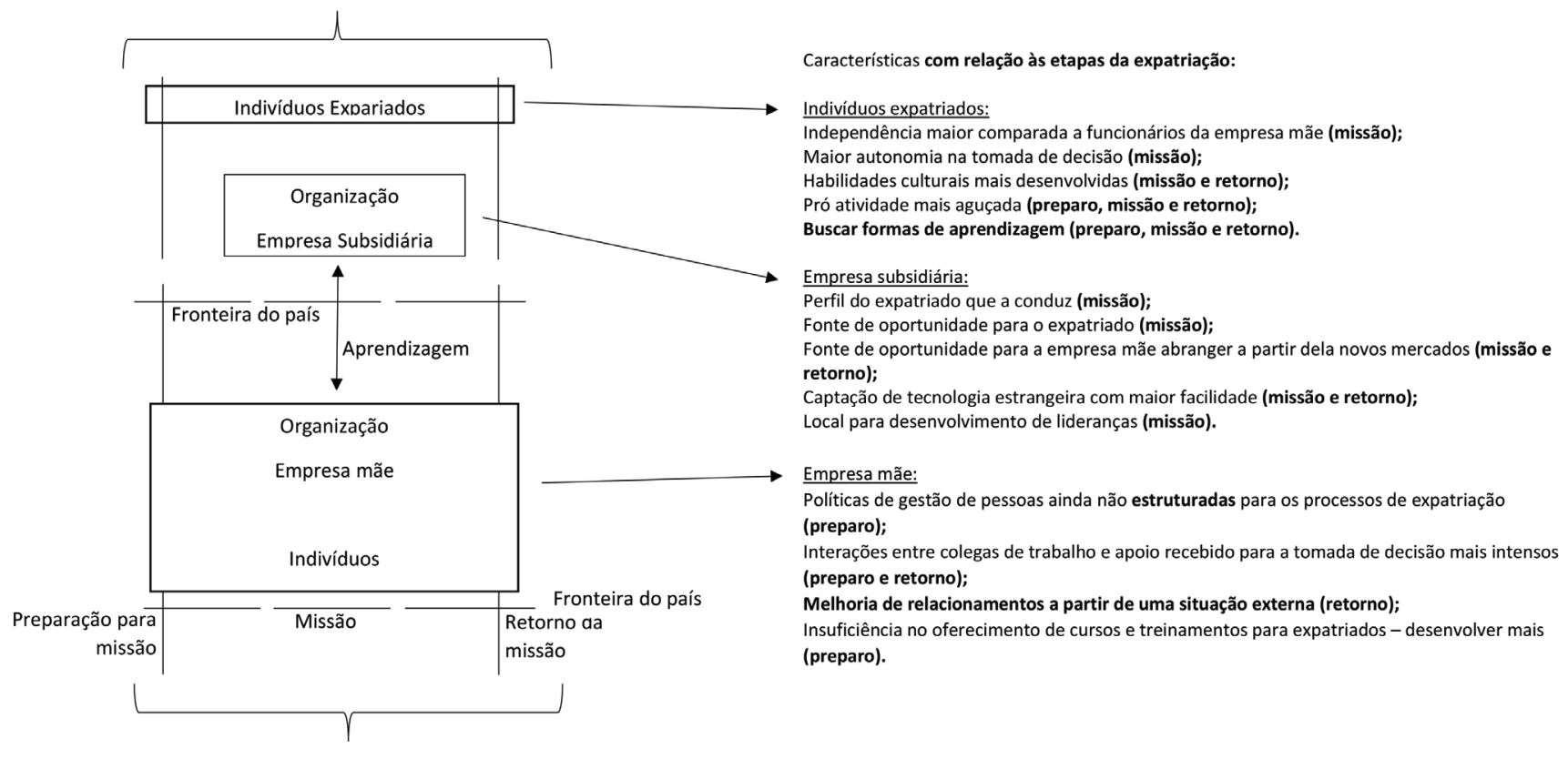

Contexto: organizações em um ambiente globalizado

Figura 4. Esquema conceitual do estudo

Fonte: elaborada pelos autores

Por outro lado, a proximidade com o mercado estrangeiro amplia as possibilidades de captação de tecnologia estrangeira, justamente porque o expatriado tende a observar o que acontece no exterior e o que os seus concorrentes internacionais lançam no mercado. A expatriação possibilita ainda o desenvolvimento de novas lideranças pelo fato dos expatriados conduzirem uma nova organização, contratarem pessoas, tomarem decisões e gerenciarem equipes, o que recebe sustentação de Cerdin e Dubouloy (2004), Plourde et al. (2014), Gallon e Scheffer (2015), Ren et al. (2015) e Whitehead (2017).

Quanto à identificação das características dos indivíduos expatriados percebeu-se uma independência e iniciativa maiores na tomada de decisão e ações de gestão quando comparado ao trabalho desenvolvido na empresa mãe, ratificando o aumento da aprendizagem e das capacidades em aspectos profissionais (Gallon \& Scheffer, 2015). Outro destaque é o fato que a dificuldade em relacionar a teoria que o expatriado aprendeu com a 
prática do cotidiano é suprida no momento em que ele busca e aproveita outras formas de aprendizagem, tais como a prática do feedback, interação, colaboração, networking e observação/modelos, com características mais informais e sociais, associadas ao conhecimento tácito dependentes do contexto (Bonache et al., 2001, Nicolini et al., 2003; Antonello, 2011; Barakat \& Moussa, 2014). Por último, tem-se o desenvolvimento das habilidades culturais, necessárias para se trabalhar e viver em outros países e, principalmente, para entender como agem empregados e clientes do país estrangeiro, o que pode estar associado às mudanças de perspectiva e de identidade, bem como à aprendizagem da vida na expatriação (González \& Oliveira, 2011; Gallon \& Scheffer, 2015).

\section{Considerações Finais}

Tendo em vista que a aprendizagem dos indivíduos pode ser considerada como um processo no qual as competências e habilidades são desenvolvidas a partir das experiências e observações vividas (Eboli, 2002), as organizações tendem a transformar essa aprendizagem individual em novos conhecimentos para manter ou melhorar seus desempenhos (Dibella \& Nevis, 1999; Prange, 2001). O objetivo geral deste trabalho foi analisar a contribuição da expatriação para os processos de aprendizagem organizacional.

Assim, na identificação e relacionamento das práticas de aprendizagem organizacional com as de expatriação e suas etapas em cada organização, o aspecto que mais ficou saliente foi o da maturidade que uma expatriação confere ao indivíduo. $\mathrm{O}$ fato de se trabalhar com menos apoio do que no país sede da empresa, de estar exposto a visões de mundo completamente diferentes e de adquirir experiências dentro do período da expatriação trazem ao indivíduo diferenciais enquanto desenvolvimento próprio, assim como no tocante ao que ele mesmo pode devolver à empresa. Também se identificou que os expatriados aprendem com questões relacionadas à dificuldade ou necessidade em resolver problemas tanto pessoais quanto profissionais, através da reflexão, da interação com colegas e da identificação da necessidade de ajuda em desenvolver determinadas características.

Além disso, a expatriação contribui para que, a partir dos aspectos de adaptação cultural, o expatriado passe a enxergar a sua própria cultura sob uma nova ótica, a tomar conhecimento de outras culturas organizacionais e a identificar novas formas de lidar com pessoas na equipe do país da empresa subsidiária. Mudanças de perspectiva e de comportamento que fizeram o expatriado modificar e repensar suas premissas, reconhecer fracassos e limitações como pessoa também foram contribuições da expatriação para os processos de aprendizagem (González \& Oliveira, 2011; Gallon \& Scheffer, 2015; Ren et al., 2015; Coelho, 2017).

A expatriação pode ser usada como um recurso efetivo de desenvolvimento pessoal e profissional que promove a aprendizagem do indivíduo, contribuindo para a organização. Constatou-se que a expatriação propiciou uma melhora na aprendizagem no contexto organizacional através 
do aprimoramento dos conhecimentos individuais pela experiência da expatriação, sob um enfoque social e cultural (Antonello, 2011; Barakat \& Moussa, 2014). Porém, as organizações devem estar atentas não apenas à implementação da estratégia de expatriação, mas, principalmente, ao acompanhamento do processo (Vianna \& Souza, 2009; Gallon \& Antunes, 2013; 2015; Gallon \& Bittencourt, 2016). Outrossim, constatou-se que a expatriação aprimorou o engajamento na busca pelo conhecimento no retorno ao trabalho na empresa mãe, remetendo a aspectos cognitivos, afetivos e sociais (Porath et al., 2011; Gonzalez \& Chakraborty, 2014; Ren et al., 2015).

Desta maneira, pode-se afirmar que os temas aprendizagem e expatriação relacionam-se e podem contribuir para que empresários definam formas de aprendizagem para aperfeiçoar suas equipes. Diante disso, este trabalho contribui para o campo organizacional por discutir a prática de gestão de pessoas e a internacionalização de empresas por meio das expatriações, além de auxiliar na compreensão do porquê as organizações serem o resultado de seus processos formais e informais de aprendizagem (Bispo \& Godoy, 2012). Isso vem ao encontro de Argote (2011), que argumenta que o assunto AO deveria ser estudado para aumentar as relações com temas atuais, preenchendo lacunas nas teorias e evidências empíricas, respondendo à evolução social e tecnológica.

Como contribuição do estudo, com foco em implicações organizacionais, percebe-se que poderia existir nas organizações uma participação maior de indivíduos repatriados na implantação e implementação de políticas de gestão de pessoas para a expatriação. Recomenda-se também que a prática da expatriação seja melhorada no futuro em ambos os lados (indivíduo e organização), de maneira que sejam efetivados, principalmente, treinamentos e propulsão de carreiras.

Esta pesquisa colabora com o estudo das práticas de gestão de pessoas que emergem das necessidades das empresas em desenvolver seus profissionais (Dutra, 2002) para atuar em mercados globalizados. Constatou-se que as expatriações contribuem tanto para seus integrantes, quanto para as organizações, pelas possibilidades de facilitar as práticas organizacionais diárias. Com isso, gerenciar os processos de expatriação torna-se um ponto chave.

Foram identificadas como limitações do estudo o fato da análise de dados depender principalmente dos resultados oriundos das entrevistas em profundidade, assim como a questão que todos os entrevistados expatriados desempenharam previamente o papel de gestores de exportação. Como sugestão de estudos futuros, indica-se que se considere a influência das culturas nacional e organizacional nos processos de aprendizagem do indivíduo expatriado e seu elo com a aprendizagem em nível organizacional. Além disso, que sejam avaliados o desenvolvimento da carreira e as competências a partir dos processos de aprendizagem individual promovidos durante a expatriação. Por fim, poderia ser trabalhada a influência do contexto político econômico brasileiro para entender os efeitos da atual situação político-econômica do país na estratégia de internacionalização das empresas. 


\section{Referências}

Adler, N. J., \& Bartholomew, S. (1992). Academic and professional communities of discourse: generating knowledge on transnational human resource management. Journal of International Business Studies, 23(3), 551-569.

Antal, A. B., (2001). Expatriates' contributions to organizational learning. Journal of General Management, 26(4), 62-84.

Antonello, C. S. (2011). Saberes no Singular? Em discussão a falsa fronteira entre a aprendizagem formal e informal. In: C. S. Antonello (org) Aprendizagem organizacional no Brasil (pp. 225-245). Porto Alegre: Bookman.

Antonello, C. S., \& Godoy, A. (2010). A encruzilhada da aprendizagem organizacional: uma visão multiparadigmática. RAC-Revista de Administração Contemporânea, 14(2), 310-322.

Argote, L. (2011). Organizational learning research: past, present and future. Management Learning, 42(4), 439-446.

Argyris, C., \& Schön, D. (1996). Organizational learning II: theory, method and practice. Massachusetts: Addison-Wesley.

Barakat, A., \& Moussa, F. (2014). Variables influencing expatriate learning and organizational learning. Competitiveness Review, 24(4), 275 - 292.

Bardin, L. (2011). Análise de Conteúdo. Lisboa: Edições, 70.

Baruch, Y., \& Altman, Y. (2002). Expatriation and repatriation in MNCs: A taxonomy. Human Resource Management, 41(2), 239-259.

Bispo, M. de S., \& Godoy, A. S. (2012). A Etnometodologia enquanto caminho teórico-metodológico para investigação da aprendizagem nas organizações. RAC-Revista de Administração Contemporânea, 16(5), 684-704.

Bonache, J., Brewster, C., \& Suutari, V. (2001). Expatriation: A developing research agenda. Thunderbird International Business Review, 43(1), 3-20.

Brasil. Lei n. 11.962, de 06 de julho de 2009. (2009). Dispõe sobre a regulamentação da situação de trabalhadores contratados no Brasil ou transferidos para prestar serviço no exterior. Brasília. 2009. Recuperado em 8 abril, 2015, de http://www. planalto.gov.br/ccivil_03/_Ato2007-2010/2009/Lei/L11962.htm.

Brasil. Ministério da Indústria, Comércio Exterior e Serviços. (2016) Estatísticas de Comércio Exterior. Recuperado em 30 setembro, 2016, de http://www.mdic.gov.br/ index.php/comercio-exterior/estatisticas-de-comercio-exterior.

Cateora, P. R., \& Graham, J. L. (2009). Marketing internacional. Rio de Janeiro: LTC.

Cavusgil, S. T.r; Knight, G. \& Riesenberger, J. R. (2010). Negócios internacionais: estratégia, gestão e novas realidades. São Paulo: Pearson Prentice Hall.

Cerdin, J.L., \& Dubouloy, M. (2004) Expatriation as a maturation opportunity: A psychoanalytical approach based on 'copy and paste'. Human Relations, 57(8), 957- 981.

Certo, S. C. (2003). Administração moderna. São Paulo: Pearson Prentice Hall.

Chang, Y. Y., \& Smale, A. (2013). Expatriate characteristics and the stickiness of HRM knowledge transfers. The International Journal of Human Resource Management, 24(12), 2394-2410. 
Chiva, R., Ghauri, P., \& Alegre, J. (2014). Organizational learning, innovation and internationalization: A complex system model. British Journal of Management, 25(4), 687-705.

Coelho Jr., F. A., \& Mourão, L. (2011). Suporte à aprendizagem informal no trabalho: uma proposta de articulação conceitual. RAM. Revista de Administração Mackenzie, 12(6), 224-253.

Coelho, J. V. (2017). Estar dentro, estando fora: da expatriação como quadro de acção disjuntivo. Gestão e Sociedade, 11(30), 1976-1999.

De Clercq, D., Sapienza, H. J., \& Crijns, H. (2005). The internationalization of small and medium-sized firms. Small business economics, 24(4), 409-419.

Dibella, A. J., \& Nevis, E. C. (1999). Como as organizações aprendem: uma estratégia integrada voltada para a construção de capacidade de aprendizagem. São Paulo: Educator.

Dutra, J. S. (2002). Gestão de pessoas: modelo, processos, tendências e perspectivas. São Paulo: Atlas.

Eboli, M. (2002). O desenvolvimento das pessoas e a educação corporativa. As pessoas na organização. São Paulo: Gente.

Easterby-Smith, M. V. P., \& Araujo, L. M. (2001). Aprendizagem organizacional: oportunidades e debates atuais. In M. P. V. Easterby-Smith, L. M. Araujo, \& J. G. Burgoyne (Orgs.). Aprendizagem organizacional e organização de aprendizagem: desenvolvimento na teoria e na prática (pp. 15-38). São Paulo: Atlas.

Eisenhardt, K. M. (1989). Building theories from case study research. Academy of management review, 14(4), 532-550.

Fee, A., Gray, S. J., \& Lu, S. (2013). Developing cognitive complexity from the expatriate experience: Evidence from a longitudinal field study. International Journal of Cross Cultural Management, 13(3), 299-318.

Flick, U. (2009). Introdução à pesquisa qualitativa. Porto Alegre: Armed.

Freitas, M. E. (2010). Expatriação profissional: o desafio interdependente para empresas e indivíduos. Revista Eletrônica Gestão e Sociedade, 4(9), 689-708.

Fundação Dom Cabral. (2017). Ranking das Multinacionais Brasileiras 2017. Recuperado em 01 junho, 2018, de https://www.fdc.org.br/conhecimento/ publicacoes/relatorio-de-pesquisa-16375.

Gallon, S., \& Antunes, E. D. D. (2013, maio). O processo de expatriação na estratégia organizacional. Anais do Congresso Instituto Franco-Brasileiro de Administração de Empresas, Tours, França, 7.

Gallon, S., \& Antunes, E. D. D. (2015). Processo de expatriação: um modelo com fases e práticas. Revista Eletrônica de Estratégia \& Negócios, 8(2), 54-85.

Gallon, S., \& Bitencourt, B. M. (2015). Programas Trainee E Expatriação Como Processos Que Evidenciam A Importância Estratégica Da Gestão De Recursos Humanos. Teoria e Prática em Administração, 5(2), 140-166.

Gallon, S., \& Scheffer, A. B. B. (2015). Expatriação: Uma Oportunidade de Repensar a Carreira. Revista Alcance (Online), 22(2), 298.

Gherardi, S. (2005). Organizational knowledge: the texture of workplace learning. London: Blackwell. 
Gherardi, S., \& Nicolini, D. (2001). The sociological foundations of organizational learning. In M. Dierkes, A. B. Antal, J. Child, \& I Nonaka (Ed.). Handbook of Organizational Learning and Knowledge (Chap. 2, pp. 35-60), Oxford: Oxford University Press.

Gong, Y. (2003). Subsidiary staffing in multinational enterprises: Agency, resources, and performance. Academy of Management journal, 46(6), 728-739.

Gonzalez, J. A., \& Chakraborty, S. (2014). Expatriate knowledge utilization and MNE performance: A multilevel framework. Human Resource Management Review, 24(4), 299-312.

González, J. M. R., \& Oliveira, J. A. (2011). Os efeitos da expatriação sobre a identidade: estudo de caso. Cadernos EBAPE.BR, 9(4), 1122-1135.

Harzing, A. W. (2001). Of bears, bumble-bees, and spiders: The role of expatriates in controlling foreign subsidiaries. Journal of World Business, 36(4), 366-379

Homem, I. D., \& Dellagnelo, E. H. L. (2006). Novas formas organizacionais e os desafios para os expatriados. RAE-eletrônica, 5(1), 1-21.

Howe-Walsh, L., \& Schyns, B. (2010). Self-initiated expatriation: implications for HRM. The International Journal of Human Resource Management, 21(2), 260-273.

Kim, D. H. (1998). O elo entre a aprendizagem individual e a aprendizagem organizacional. Klein, Da. A gestão estratégica do capital intelectual: recursos para a economia baseada em conhecimento. Rio de Janeiro: Qualitymark, 61-92.

Klotzle, M. C. (2002). Alianças estratégicas: conceito e teoria. Revista de Administração contemporânea, 6(1), 85-104.

Larentis, F., Antonello, C. S., Milan, G. S., \& De Toni, D. (2014). Aprendizagem organizacional e relacionamentos interorganizacionais: um estudo de casos múltiplos. Revista Base (Administração e Contabilidade) da UNISINOS, 11(4), 347-366.

Malcolm, J., Hodkonson, P., \& Colley, H. (2003). The interrelationships between informal and formal learning. Journal of workplace learning, 15(7/8), 313-318.

March, J. G., \& Olsen, J. P. (1975). The uncertainty of the past: Organizational learning under ambiguity. European journal of political research, 3(2), 147-171.

Moreira, M. Z., Norões, J. L., \& Ogasavara, M. H. (2014). Framework da estratégia de expatriação no âmbito do indivíduo, da organização e do ambiente internacional. Apresentação, 9(1), 81-100.

Niessen, C., Sonnentag, S., \& Sach, F. (2012). Thriving at work - A diary study. Journal of Organizational Behavior, 33(4), 468-487.

Nicolini, D., Gherardi, S., \& Yanow, D. (2003). Introduction: Toward a practicebased view of knowledge and learning in organization. In D. Nicolini, S. Gherardi, \& D. Yanow (Orgs.). Knowing in organizations: a practice-based approach (Cap. 1, pp. 3-31). New York: M. E. Sharpe.

Nogueira, R. A., \& Odelius, C. C. (2015). Desafios da pesquisa em aprendizagem organizacional. Cadernos EBAPE. BR, 13(1).

Nonaka, I., Toyama, R., \& Hirata, T. (2011). Managing Flow: teoria e casos de empresas baseadas no conhecimento. Porto Alegre: Brookman. 
Oddou, G., Osland, J. S., \& Blakeney, R. N. (2009). Repatriating knowledge: Variables influencing the "transfer" process. Journal of international business studies, 40(2), 181-199.

Park, K., \& Mense-Petermann, U. (2014). Managing across borders: Global integration and knowledge exchange in MNCs. Competition \& Change, 18(3), 265-279.

Plourde, Y., Parker, S. C., \& Schaan, J. L. (2014). Expatriation and its effect on headquarters' attention in the multinational enterprise. Strategic Management Journal, 35(6), 938-947.

Porath, C., Spreitzer, G., Gibson, C., \& Garnett, F. G. (2012). Thriving at work: Toward its measurement, construct validation, and theoretical refinement. Journal of Organizational Behavior, 33(2), 250-275.

Prange, C. (2001). Aprendizagem organizacional: desesperadamente em busca de teorias. In M. P. V. Easterby-Smith, L. M Araujo, \& J. G. Burgoyne (Orgs.). Aprendizagem organizacional e organização de aprendizagem: desenvolvimento na teoria e na prática (pp. 41-63). São Paulo: Atlas.

Prestes, V. A., Grisci, C. L. I., \& Fraga, A. M. (2016). Lifestyles of workers in the expatriation context. RAM. Revista de Administração Mackenzie, 17(3), 39-59.

Rahim, A. (1983). A model for developing key expatriate executives. Personnel Journal, 62(4), 313-318.

Ramaswami, A., Carter, N. M., \& Dreher, G. F. (2016). Expatriation and career success: A human capital perspective. Human relations, 69(10), 1959-1987.

Ren, H., Yunlu, D. G., Shaffer, M., \& Fodchuk, K. M. (2015). Expatriate success and thriving: The influence of job deprivation and emotional stability. Journal of World Business, 50(1), 69-78.

Rose, R. C., Ramalu, S. S., Uli, J., \& Kumar, N. (2010). Expatriate performance in international assignments: The role of cultural intelligence as dynamic intercultural competency. International Journal of Business and Management, 5(8), 76.

Schön, D. A. (1983). Organizational learning. In: MORGAN, G. (Ed.) Beyond method. Beverly Hills, CA: Sage.

Sebben, A., \& Dourado F. F. (2010). Os nortes da bússola: manual para conviver e negociar com culturas estrangeiras. Porto Alegre: Artes e Ofícios.

Selmer, J., \& Suutari, V. (2011). Expatriation-old issues, new insights. Cross Cultural Management: An International Journal, 18(2), 150-160.

Shah, D., \& Barker, M. (2017). Cracking the cultural code: Indian IT expatriates' intercultural communication challenges in Australia. International Journal of CrossCultural Management, 17(2), 215-236.

Silbiger, A., Berger, R., Barnes, B. R., \& Renwick, D. (2017). Improving expatriation success: the roles of regulatory focus and burnout. British Journal of Management, 28(2), 231-247.

Tan, D., \& Mahoney, J. T. (2006). Why a multinational firm chooses expatriates: Integrating resource-based, agency and transaction costs perspectives. Journal of Management Studies, 43(3), 457-484.

Tanure, B., Evans, P., \& Pucik, V. (2007). Virtudes e pecados capitais: a gestão de pessoas no Brasil. Rio de Janeiro: Campus. 
Vergara, S. C. (2005). Métodos de pesquisa em administração. São Paulo: Atlas.

Vianna, N. P., \& Swirski, Y. S. (2009). Uma análise sobre os processos de expatriação e repatriação em organizações brasileiras. Revista Base, 6(4), 340-353.

Weick, K., \& Westley, F. (2004). Organizational learning: affirm and oxymoron, In S. Clegg, C. Hardy, \& W. R Nord (org.). Handbook of Organizational Studies. Londres: Sage.

Whitehead, G. (2017). The contradictory condition of 'homelessness' in the life of the transnational professional. Culture and Organization, 23(4), 306-324.

Yin. R. K. (2010). Estudo de caso: planejamento e métodos. Porto Alegre: Bookman. 